\title{
Optimum insurance contract of flood damage index insurance for rice farmers in Myanmar
}

\author{
Jun Furuya ${ }^{1}\left[\right.$ D Swe Swe Mar $^{2} \cdot$ Akira Hirano $^{1} \cdot$ Takeshi Sakurai $^{3}$
}

Received: 30 December 2020 / Revised: 25 May 2021 / Accepted: 27 May 2021 / Published online: 21 June 2021

(c) The Author(s) 2021

\begin{abstract}
Climate change is an underlying cause of many extreme events such as enormous cyclones and erratic torrential rains. These phenomena threaten farmers in coastal regions of Myanmar. Self-insurance through means such as crop diversification is insufficient for sustainable farm management. Weather index insurance (WII) is receiving much attention because of its low management costs. An optimum WII contract for flood damage using rainfall as the index has been proposed for rice farmers in coastal regions. According to the model, an insurance payment demand function is derived by solving the expected utility maximization problem. The utility function of the contract is specified as constant relative risk aversion type. The production function is specified as Cobb-Douglas type. By substituting real average data of rice production of farmers into this function, the optimum insurance payment and premium are obtained. Changes in insurance compensation by payments according to an increase in the price of rice, rainfall, and degree of risk aversion are investigated. Results suggest that if an average farmer pays around 41.5 US dollars per year, then farm management will be optimally stabilized under the flood risk.
\end{abstract}

Keywords Constant relative risk aversion $\cdot$ Insurance payment $\cdot$ Myanmar $\cdot$ Optimum contract $\cdot$ Weather index insurance

\section{Introduction}

Air temperatures have increased worldwide by $1{ }^{\circ} \mathrm{C}$ during the last 100 years. The Intergovernmental Panel on Climate Change (IPCC) forecasts that air temperatures will increase by $1.4-3.1^{\circ} \mathrm{C}$ by the end of this century. Climate change can give rise to extreme events such as increasing drought stress, occurrence of high tides, and activation of tropical cyclones (IPCC 2015: p60).

The cyclone Nargis, having size and power on an unprecedented scale, struck the Ayeyarwady region in Myanmar on 2 May 2008. In its wake, the cyclone left severe damage

Jun Furuya

furuya@affrc.go.jp

1 Social Sciences Division, International Research Center for Agricultural Sciences, 1-1 Ohwashi, Tsukuba, Ibaraki 305-8686, Japan

2 Department of Soil and Water Science, Yezin Agricultural University, Yezin, Nay Pyi Taw, Myanmar

3 Department of Agricultural and Resource Economics, Graduate School of Agricultural and Life Sciences, The University of Tokyo, 1-1-1 Yayoi, Bunkyo-ku, Tokyo 113-8657, Japan in the region, with 140 thousand people dead or missing (Fritz et al. 2009). Damage to the agricultural sector in this region was not severe because the cyclone struck before rice planting. Nevertheless, the cyclone washed away agricultural materials and animals such as draft cattle. Above all, the region lost many residents to this disaster.

For revitalization after the disaster, rice seed was brought in huge quantities from other regions of Myanmar. One hand tractor per 100 acres was provided. For instance, seven tractors and six cattle were provided to Thin Gan Lay village in the Sin Chay Yar village tract in 2008. Furthermore, during the year following the disaster, dykes were constructed by the World Bank in Labutta township to prevent saltwater intrusion.

Surveys of farmers conducted by the authors revealed that rice yields in 2009, the year after Nargis struck, decreased because of high soil salinity. Furthermore, Htwe et al. (2013) reported that rice crops were damaged by rodent outbreaks that year. Farmers' incomes in the year after the cyclone hit decreased according to this downward spike in production. However, according to survey responses, $10.4 \%$ of farmers in the township were adversely affected by flooding during the 9 years following the cyclone disaster. Flooding of two types occurred, i.e., river flooding and inundation inside a 
levee. Strong cyclones and tropical atmospheric pressures cause these two types of inundation in low-lying coastal areas. Development of insurance for agricultural production is desired for preventing the deterioration of farmers' economic conditions as a result of climate change and for assisting the rehabilitation efforts of farmers.

Self-insurance such as crop diversification and animal rearing are costly for farmers with small landholdings. By implementing efficient risk management, crop insurance has been developed in some economically developed countries. The government of Myanmar approved a crop insurance program for local farmers in 2018.

However, normal crop insurance requires the dispatch of investigators after disasters. Therefore, insurance companies and local governments must bear the costs and time necessary for insurance payments to contracting farmers affected by a disaster. In these economically developing countries, where the budgets of farmers are difficult to manage, the introduction of expensive crop insurance is difficult. To compensate for the shortcomings of conventional crop insurance, weather index insurance (WII) has been developed. For example, if the target of the insurance is drought, then the insurance company will pay out insurance compensation to the contracted farmers if rainfall is less than some previously determined threshold amount. The World Bank (2011) summarizes differences between crop insurance and WII.

The WII presents two important benefits: (1) widening of choices of cultivated crops (Cole et al. 2017) and (2) increased agricultural inputs such as fertilizer and land (Hill and Viceisza 2012). The former benefit engenders the introduction of riskier crops such as tobacco and cotton.

However, de Janvry et al. (2017) reported that if the government does not reduce the WII price by providing a subsidy, then demand for this insurance will be low. Introducing salt-tolerant or drought-tolerant cultivars to farmers in disaster-prone regions is another effective choice because the seed price is the same as that of traditional varieties in many cases, because decreases in the yields of crops in a disaster year are small, and because the yield in a normal year is higher than those of traditional varieties. Nevertheless, development of these disaster-tolerant cultivars takes many years. Therefore, farmers find great difficulty in selecting such cultivars immediately. In such a situation, WII is an important adaptation measure for disasters caused by climate change.

Some demand analyses of WII can be made using data obtained from choice experiments. For instance, McIntosh et al. (2013) used a contingent valuation method to infer the willingness to pay (WTP) for WII. They inferred that stated and actual demands i.e., ex ante and ex post demands, differ. Karlan et al. (2014) estimated demand functions of rainfall index insurance. Their results revealed that the insurance increases farmers' investment in labor and capital. The insurance engenders a shift from mixed cultivation to rainfall-sensitive maize cultivation. Their finding is noteworthy: demand for insurance bundled with credit is overestimated because of the potential for default of the credit component of the contract.

Akter et al. (2016) analyzed differences between men and women in their demand for WII. Results show that farmers who are women avoided selecting WII because of their low financial literacy. Jin et al. (2016) estimated a demand function of WII for the coefficient of relative risk aversion. They found that risk-averse farmers will use WII. Belissa et al. (2019) used data from experiments to calculate the constant relative risk aversion (CRRA) and constant relative ambiguity aversion under the CRRA utility function. They concluded that if the degree of risk aversion increases and if the ambiguity level decreases, then the demand for WII can be expected to increase.

Empirical studies have specifically examined demand analyses using data from field experiments. A comprehensive approach is necessary for actual studies. Shirsath et al. (2019) developed an integrated system for designing WII including a crop model and a farmer satisfaction index. Information from such systematic approaches is important not only for farmers but also for WII underwriters.

This study is intended to offer a design of a WII which stabilize farm income in disaster-prone regions. Therefore, the target area was selected from the coastal region in a main rice production region, i.e., the Ayeyarwady Region.

This study was conducted to derive optimum insurance payments and premium by which farmers can conduct sustainable management considering the behavior of insurance companies under flood risk and economic constraints. This article comprises the following sections. First, an optimum insurance contract design is proposed. By solving the expected utility maximization problem, an insurance payment demand function is obtained. Second, data for calculating optimum insurance payments and premiums are presented. Third, changes in the optimum insurance payments and premiums according to increases in the output price, rainfall, and the coefficient of relative risk aversion are investigated. Finally, the feasibility and a future scheme for the proposed WII are stated.

\section{Designing the optimum insurance contract}

An insurance model for insurance payments given as compensation to farmers who sustain flood damage when rainfall exceeds a threshold level was designed for ten village tracts in Labutta township of the Ayeyarwady region in Myanmar. All farmers sustained cyclone damage in 2008.

The theoretical model is based on that described by Mahul (2001). This model is designed for obtaining 
optimum insurance payments and a premium. The farmers in this model are assumed to be risk-averse. The utility function is specified as CRRA type because input demand functions were not obtainable by functions of any type except quadratic function. Considering changes in the risk aversion rate, the CRRA-type function was selected in this model. The production function of the farmers is specified as Cobb-Douglas type for ease of calculation. The model for the optimum insurance contract is assumed according to the following procedure. First, an insurance company will estimate the optimum input demand of farmers. Second, the insurance company will calculate the optimum insurance payment for farmers using the obtained optimum inputs. Finally, the insurance company will account for their insurance premium using the insurance payment and flood disaster probability.

The optimization problem for the insurance contract is the following.

$\max . E[u(R)]$

s.t. $u(R)=\frac{R^{1-\gamma}-1}{1-\gamma}$

$R=\pi+I(Z) / n-I R$

$\pi=p q-w_{V} x_{V}-w_{L} x_{L}-w_{K} x_{K}-w_{S} x_{S}$

$q=\left(1-\frac{\omega}{100}\right) x_{V}^{\beta V} x_{L}^{\beta L} x_{K}^{\beta K} x_{S}^{\beta S}$

$I(Z)=p q \frac{\theta}{100} \max (B-Z, 0)$

$I R-I(Z) / n=c_{T}$

$\omega^{E}=E\left[\omega \mid B_{\text {May }}, \ldots, B_{\text {Oct }}\right]$

$\theta^{E}=E\left[\theta \mid B_{\mathrm{May}}, \ldots, B_{\mathrm{Oct}}\right]$

$\theta=\frac{\partial \omega}{\partial B}, \omega=\int \theta d B$

$c_{T}=m p q$

Variables used for this model are presented below: $\gamma$ is the coefficient of relative risk aversion (CoRRA), where the preference is risk neutral if $\gamma=0$. However, if $\gamma>0$, then the preference is risk aversion: $\gamma \neq 1$. In addition, $R$ represents the profit of farmers who contract for the insurance. $\pi$ denotes agricultural profit (Kyat). In addition, $I(Z)$ stands for the insurance payment (Kyat). $Z$ is the threshold of rainfall $(\mathrm{mm})$. Additionally, $I R$ stands for insurance premium (Kyat), $n$ denotes the contract year of this insurance, $p$ expresses the price of agricultural products (Kyat $\mathrm{kg}^{-1}$ ), and $q$ signifies the quantity of production $(\mathrm{kg})$. In addition, $w_{V}, w_{L}, w_{K}$, and $w_{S}$, respectively, represent the price of fertilizer $\left(\mathrm{Kyat} \mathrm{kg}^{-1}\right)$, wage rate (Kyat person ${ }^{-1}$ day $^{-1}$ ), capital user cost price (000 Kyat tractor $\left.{ }^{-1}\right)$, and the land rent $\left(000 \mathrm{Kyat} \mathrm{acre}^{-1}\right)$. In addition, $x_{V}, x_{L}, x_{K}$, and $x_{S}$, respectively, denote the fertilizer input (kg), labor input (person day), capital input (harvest fee 000 Kyat), and land input (acre). In addition, $\omega$ stands for the rate of damaged area (\%), $\theta$ expresses the marginal rate of damaged area to rainfall (\%), $B$ denotes rainfall (mm), $c_{T}$ signifies the transaction cost of introducing the insurance for the insurance company, and $m$ represents the margin rate.

Substituting production function (5) into Eq. (4) and substituting its profit equation, Eqs. (7), and (11) into Eq. (3), the following equation of profit is obtained for farmers who buy the insurance.

$$
\begin{aligned}
R= & (1-m) p\left(1-\frac{\omega}{100}\right) x_{V}^{\beta V} x_{L}^{\beta L} x_{K}^{\beta K} x_{S}^{\beta S}-w_{V} x_{V}-w_{L} x_{L} \\
& -w_{K} x_{K}-w_{S} x_{S}
\end{aligned}
$$

The expected value of the objective utility function is the following.

$E[u(R)]=E\left[\frac{R^{1-\gamma}-1}{1-\gamma}\right]=\frac{E\left[R^{1-\gamma}\right]-1}{1-\gamma}$

The following first-order condition is obtained if Eq. (13) is differentiated by fertilizer input $x_{V}$.

$E\left[\frac{\partial u(R)}{\partial x_{V}}\right]=E\left[R^{-\gamma} \frac{\partial R}{\partial x_{V}}\right]$

$=E\left[R^{-\gamma} \beta_{V}(1-m) p\left(1-\frac{\omega}{100}\right) x_{V}^{\beta V-1} x_{L}^{\beta L} x_{K}^{\beta K} x_{S}^{\beta S}-w_{V}\right]=0$

The following equation is obtained if the equation in the expectation parenthesis is expanded.

$$
\begin{aligned}
& \beta_{V}(1-m) p x_{V}^{\beta V-1} x_{L}^{\beta L} x_{K}^{\beta K} x_{S}^{\beta S} R^{-\gamma}-\beta_{V}(1-m) p x_{V}^{\beta V-1} \\
& x_{L}^{\beta L} x_{K}^{\beta K} x_{S}^{\beta S} \frac{R^{-\gamma} \omega}{100}-w_{V}
\end{aligned}
$$

By substituting Eq. (15) into the expectation Eq. (14), the following equation is obtained.

$\beta_{V}(1-m) p x_{V}^{\beta V-1} x_{L}^{\beta L} x_{K}^{\beta K} x_{S}^{\beta S}\left(E\left[R^{-\gamma}\right]-\frac{E\left[R^{-\gamma} \omega\right]}{100}\right)=w_{V}$

The characteristics of the covariance engender derivation of the following formula. 
$E\left[R^{-\gamma} \omega\right]=E\left[R^{-\gamma}\right] E[\omega]+\operatorname{cov}\left(R^{-\gamma}, \omega\right)$

$\therefore f(R) \approx \frac{1}{\alpha^{\gamma}}-\frac{\gamma}{\alpha^{\gamma+1}}(R-\alpha)=\frac{1}{\alpha^{\gamma}}\left[1-\frac{\gamma}{\alpha}(R-\alpha)\right]$

By substituting the formula into Eq. (16), the following equation is found for fertilizer input $x_{V}$.

$\beta_{V}(1-m) p x_{V}^{\beta V-1} x_{L}^{\beta L} x_{K}^{\beta K} x_{S}^{\beta S}\left(E\left[R^{-\gamma}\right]-\frac{E\left[R^{-\gamma}\right] E[\omega]+\operatorname{cov}\left(R^{-\gamma}, \omega\right)}{100}\right)=w_{V}$

In a similar fashion, the first-order conditions for labor input $x_{L}$, capital input $x_{K}$, and land input $x_{S}$ are obtained.
If $\alpha$ is the mean of $R$, i.e., $\bar{R}$, then the following approximation is obtained.

$\beta_{L}(1-m) p x_{V}^{\beta V} x_{L}^{\beta L-1} x_{K}^{\beta K} x_{S}^{\beta S}\left(E\left[R^{-\gamma}\right]-\frac{E\left[R^{-\gamma}\right] E[\omega]+\operatorname{cov}\left(R^{-\gamma}, \omega\right)}{100}\right)=w_{L}$

$\beta_{K}(1-m) p x_{V}^{\beta V} x_{L}^{\beta L} x_{K}^{\beta K-1} x_{S}^{\beta S}\left(E\left[R^{-\gamma}\right]-\frac{E\left[R^{-\gamma}\right] E[\omega]+\operatorname{cov}\left(R^{-\gamma}, \omega\right)}{100}\right)=w_{K}$

$\beta_{S}(1-m) p x_{V}^{\beta V} x_{L}^{\beta L} x_{K}^{\beta K} x_{S}^{\beta S-1}\left(E\left[R^{-\gamma}\right]-\frac{E\left[R^{-\gamma}\right] E[\omega]+\operatorname{cov}\left(R^{-\gamma}, \omega\right)}{100}\right)=w_{S}$

Dividing Eqs. (19)-(21) by Eq. (18), the following equations are obtained.

$x_{L}=\frac{\beta_{L}}{\beta_{V}} \frac{w_{V}}{w_{L}} x_{V}$

$x_{K}=\frac{\beta_{K}}{\beta_{V}} \frac{w_{V}}{w_{K}} x_{V}$

$x_{S}=\frac{\beta_{S}}{\beta_{V}} \frac{w_{V}}{w_{S}} x_{V}$

One must consider the expectation of $R^{-\gamma}$. Taylor expansion is applied to this problem because the expansion of $R^{-\gamma}$ is difficult. Taylor expansion of $f(R)$ around $R=\alpha$ is the following if $f(R)=R^{-\gamma}$.

$$
\begin{aligned}
f(R) & =\sum_{k=0}^{\infty} \frac{f^{(k)}(\alpha)}{k !}(R-\alpha)^{k} \\
& =f(\alpha)+\frac{f^{\prime}(\alpha)}{1 !}(R-\alpha)+\frac{f^{\prime \prime}(\alpha)}{2 !}(R-\alpha)^{2}+\cdots+\frac{f^{(k)}(\alpha)}{k !}(R-\alpha)^{k}+\cdots
\end{aligned}
$$

$R^{-\gamma} \approx \frac{1}{\bar{R}^{\gamma}}\left[1-\frac{\gamma}{\bar{R}}(R-\bar{R})\right]$

The expectation of $R^{-\gamma}$ is the following.

$$
E\left[R^{-\gamma}\right] \approx \frac{1}{\bar{R}^{\gamma}}\left[1-\frac{\gamma}{\bar{R}}(E[R]-\bar{R})\right]
$$

By substituting expectation $R$ of Eq. (12) into Eq. (27), the following expectation of $R^{-\gamma}$ is obtained.
For simplicity, first-order expansion is adopted in this model.

$$
f(\alpha)=\frac{1}{\alpha^{\gamma}}, f^{\prime}(\alpha)=-\gamma \alpha^{-\gamma-1}=-\frac{\gamma}{\alpha^{\gamma+1}},
$$


$E\left[R^{-\gamma}\right]=\frac{1}{\bar{R}^{\gamma}}\left\langle 1-\frac{\gamma}{\bar{R}}\left\{p(1-m)\left(1-\frac{E[\omega]}{100}\right) x_{V}^{\beta V} x_{L}^{\beta L} x_{K}^{\beta K} x_{S}^{\beta S}-w_{V} x_{V}-w_{L} x_{L}-w_{K} x_{K}-w_{S} x_{S}-\bar{R}\right\}\right\rangle$

For deriving the input demand function of fertilizer $x_{V}$, Eqs. (22)-(24) and (28) are substituted into Eq. (18).

$$
\begin{aligned}
& \beta_{V} p(1-m)\left(1-\frac{E[\omega]}{100}\right) \times \beta_{L}^{\beta L} \beta_{K}^{\beta K} \beta_{S}^{\beta S} \\
& \beta_{V}^{-\beta L-\beta K-\beta S} w_{V}^{\beta L+\beta K+\beta S} w_{L}^{-\beta L} w_{K}^{-\beta K} w_{S}^{-\beta S} x_{V}^{\beta V+\beta L+\beta K+\beta S-1} \\
& \quad \times \frac{1}{\bar{R}}\left\langle 1-\frac{\gamma}{\bar{R}}\left\{p(1-m)\left(1-\frac{E[\omega]}{100}\right)\right.\right. \\
& \quad \times \beta_{L}^{\beta L} \beta_{K}^{\beta K} \beta_{S}^{\beta S} \beta_{V}^{-\beta L-\beta K-\beta S} w_{V}^{\beta L+\beta K+\beta S} \\
& w_{L}^{-\beta L} w_{K}^{-\beta K} w_{S}^{-\beta S} x_{V}^{\beta V+\beta L+\beta K+\beta S} \\
& \left.\left.-w_{V} x_{V}-\frac{\beta_{L}}{\beta_{V}} w_{V} x_{V}-\frac{\beta_{K}}{\beta_{V}} w_{V} x_{V}-\frac{\beta_{S}}{\beta_{V}} w_{V} x_{V}-\bar{R}\right\}\right\rangle \\
& -\beta_{V} p(1-m) \beta_{L}^{\beta L} \beta_{K}^{\beta K} \beta_{S}^{\beta S} \\
& \beta_{V}^{-\beta L-\beta K-\beta S} w_{V}^{\beta L+\beta K+\beta S} w_{L}^{-\beta L} w_{K}^{-\beta K} w_{S}^{-\beta S} \\
& \quad \times x_{V}^{\beta V+\beta L+\beta K+\beta S-1} \frac{\operatorname{cov}\left(R^{-\gamma}, \omega\right)}{100}=w_{V}
\end{aligned}
$$

The production function is assumed as homogeneous of degree one in this model. In this case, the summation of the production parameter is one.
By substituting Eq. (30) into Eq. (29), the following equation is obtained.

$$
\begin{aligned}
p(1-m) & \left(1-\frac{E[\omega]}{100}\right) \beta_{L}^{\beta L} \beta_{K}^{\beta K} \beta_{S}^{\beta S} \beta_{V}^{\beta V} w_{V}^{1-\beta V} w_{L}^{-\beta L} w_{K}^{-\beta K} w_{S}^{-\beta S} \\
& \times \frac{1}{\bar{R}}\left\langle 1-\frac{\gamma}{\bar{R}}\left\{p(1-m)\left(1-\frac{E[\omega]}{100}\right) \beta_{L}^{\beta L} \beta_{K}^{\beta K} \beta_{S}^{\beta S}\right.\right. \\
& \beta_{V}^{-1+\beta V} w_{V}^{1-\beta V} w_{L}^{-\beta L} w_{K}^{-\beta K} w_{S}^{-\beta S} x_{V} \\
& \left.\left.-\frac{w_{V}}{\beta_{V}} x_{V}-\bar{R}\right\}\right\rangle-p(1-m) \beta_{L}^{\beta L} \beta_{K}^{\beta K} \beta_{S}^{\beta S} \beta_{V}^{\beta V} w_{V}^{1-\beta V} w_{L}^{-\beta L} w_{K}^{-\beta K} w_{S}^{-\beta S} \\
\times & \frac{\operatorname{cov}\left(R^{-\gamma}, \omega\right)}{100}=w_{V}
\end{aligned}
$$

The following variable is introduced for convenience.

$$
\begin{aligned}
A & =p(1-m) \beta_{L}^{\beta L} \beta_{K}^{\beta K} \beta_{S}^{\beta S} \beta_{V}^{\beta V} w_{V}^{-\beta V} w_{L}^{-\beta L} w_{K}^{-\beta K} w_{S}^{-\beta S} \\
& =p(1-m)\left(\frac{\beta_{V}}{w_{V}}\right)^{\beta V}\left(\frac{\beta_{L}}{w_{L}}\right)^{\beta L}\left(\frac{\beta_{K}}{w_{K}}\right)^{\beta K}\left(\frac{\beta_{S}}{w_{S}}\right)^{\beta S}
\end{aligned}
$$

By substituting Eqs. (32) into (31) and by rearranging it for fertilizer input $x_{V}$, the following input demand function of fertilizer is obtained.

$\left.\left.\begin{array}{l}\beta_{V}+\beta_{\psi}+\beta_{K}+\beta_{S}=1 \\ x_{V}=\left\langle\bar{R}-\left\{\left(1+A \frac{\operatorname{cov}\left(R^{-\gamma}, \omega\right)}{100}\right)\left(1-\frac{E[\omega]}{100}\right)^{-1} \frac{\bar{R}^{\gamma}(30)}{A}-1\right.\right.\end{array}\right\} \frac{\bar{R}}{\gamma}\right\rangle\left[\left(1-\frac{E[\omega]}{100}\right) A-1\right]^{-1} \frac{\beta_{V}}{w_{V}}$

Furthermore, labor, capital, and land input demand functions are obtained similarly.

$$
\begin{aligned}
& x_{L}=\left\langle\bar{R}-\left\{\left(1+A \frac{\operatorname{cov}\left(R^{-\gamma}, \omega\right)}{100}\right)\left(1-\frac{E[\omega]}{100}\right)^{-1} \frac{\bar{R}^{\gamma}}{A}-1\right\} \frac{\bar{R}}{\gamma}\right\rangle\left[\left(1-\frac{E[\omega]}{100}\right) A-1\right]^{-1} \frac{\beta_{L}}{w_{L}} \\
& x_{K}=\left\langle\bar{R}-\left\{\left(1+A \frac{\operatorname{cov}\left(R^{-\gamma}, \omega\right)}{100}\right)\left(1-\frac{E[\omega]}{100}\right)^{-1} \frac{\bar{R}^{\gamma}}{A}-1\right\} \frac{\bar{R}}{\gamma}\right\rangle\left[\left(1-\frac{E[\omega]}{100}\right) A-1\right]^{-1} \frac{\beta_{K}}{w_{K}} \\
& x_{S}=\left\langle\bar{R}-\left\{\left(1+A \frac{\operatorname{cov}\left(R^{-\gamma}, \omega\right)}{100}\right)\left(1-\frac{E[\omega]}{100}\right)^{-1} \frac{\bar{R}^{\gamma}}{A}-1\right\} \frac{\bar{R}}{\gamma}\right\rangle\left[\left(1-\frac{E[\omega]}{100}\right) A-1\right]^{-1} \frac{\beta_{S}}{w_{S}}
\end{aligned}
$$


Next, a supply function will be derived using these input demand functions. Production $q$ is a function of the damaged area rate $\omega$, which is a stochastic variable. The following expectation production function is set.

$E[q]=\left(1-\frac{E[\omega]}{100}\right) x_{V}^{\beta V} x_{L}^{\beta L} x_{K}^{\beta K} x_{S}^{\beta S}$

Substituting input demand function (33)-(36) into production function (37) and assuming production that is homogeneous of degree one, for the production, the following supply function is obtained.
2008-2016 and the causes of the damage, as well as farmer characteristics such as age, education level, and years of experience in 2016, changes in owned land and the presence of weather hazards, harvested areas, productions, prices of rice in each plot, existence of irrigation facilities, varieties of rice planted, the cropping calendar, remittance from expatriate labor, and consumption on the farm.

Table 1 presents characteristics of the surveyed farmers. The data show that more than $80 \%$ of the heads of farming households are male. The average age of the head of a farming household is 50 years old. All of the farmers are

$E[q]=\left(1-\frac{E[\omega]}{100}\right)\left\langle\bar{R}-\left\{\left(1+A \frac{\operatorname{cov}\left(R^{-\gamma}, \omega\right)}{100}\right)\left(1-\frac{E[\omega]}{100}\right)^{-1} \frac{\bar{R}^{\gamma}}{A}-1\right\} \frac{\bar{R}}{\gamma}\right\rangle\left[\left(1-\frac{E[\omega]}{100}\right) A-1\right]^{-1} \times \frac{A}{p(1-m)}$

The expected insurance payment is

$E[I(Z)]=p E[q] \frac{E[\theta]}{100} \max (B-Z, 0)$

Substituting supply function (38) into insurance payment Eq. (39), the following expectation insurance payment demand function is obtained.
Buddhist. The share of Barmar people is $99.7 \%$. This table also presents summary of their educational background, which reveals that $34.4 \%$ of farmers completed primary school, $9.4 \%$ of farmers completed secondary school, and $7.5 \%$ of farmers completed tertiary school. The national level of enrollment in 2018 reported by UNESCO was $97.9 \%$ for primary school, $64.1 \%$ for secondary school, and $18.8 \%$

$E[I(Z)]=\left(1-\frac{E[\omega]}{100}\right)\left\langle\bar{R}-\left\{\left(1+A \frac{\operatorname{cov}\left(R^{-\gamma}, \omega\right)}{100}\right)\left(1-\frac{E[\omega]}{100}\right)^{-1} \frac{\bar{R}^{\gamma}}{A}-1\right\} \frac{\bar{R}}{\gamma}\right\rangle\left[\left(1-\frac{E[\omega]}{100}\right) A-1\right]^{-1} \times \frac{A}{1-m} \frac{E[\theta]}{100} \max (B-Z, 0)$

This equation represents the average demand of insurance payment per year. However, the eventuality of exceeding the rainfall threshold occurs once every several years. For example, the frequency of exceeding $3500 \mathrm{~mm}$ of summation of rainfall during May-October is approximately once every 5 years. Therefore, the contract year of this insurance was set to 5 years. In this year, the payout of insurance payments in a damaged year is the number of Eq. (40) multiplied by the contract year of this insurance.

The probability of the farmers sustaining flood damage is $\omega \%$ per year. The expected insurance premium per year is calculable from Eqs. (7) and (11)

$\mathrm{E}[I R]=\mathrm{E}[I(Z)] / n+m p \mathrm{E}[q]$.

\section{Data}

Ten village tracts along the Thet Ke Thaung River of Labutta township in the Ayeyarwady Region were used as the target area. From lists of the farmers, 32 farmers per village tract were selected randomly. Figure 1 portrays the locations of the ten village tracts. The farm surveys were conducted in March 2017. The survey items were damaged areas during for tertiary school, respectively. Those of surveyed farmers were, respectively, $85.9 \%, 48.5 \%$, and $19.1 \%$. Therefore, the percentage of farmers who had received no education in this survey region was greater than the national figure. Moreover, the percentage of highly educated farmers in this region was greater than national level. This educational profile is expected to affect the risk attitudes of these farmers.

This table also shows that the years of agricultural activity experience of these farmers is 23.8 years. The share of farmers who have a side job is $24.1 \%$, Also, the share of rice income to total household income is $94.9 \%$. Six farmers catch fish, six farmers sell bamboo, five farmers raise livestock, and four farmers make salt.

Data used for these analyses are the respective costs and prices of fertilizer and seed, family labor input, hired labor cost, machine user cost, planted area of rice, and the production quantity and price of rice. The wage rate and land price are set, respectively, as 3,000 Kyat person ${ }^{-1}$ day $^{-1}$ and $326,000 \mathrm{Kyat}^{\mathrm{acre}}{ }^{-1}$ based on the national average (Thein et al. 2018). The national average numbers were close to the numbers in the survey region because the Ayeyarwady Region is the main rice-producing region in this country. The capital user cost price is also calculated using the tractor price, depreciation year, and average interest. 


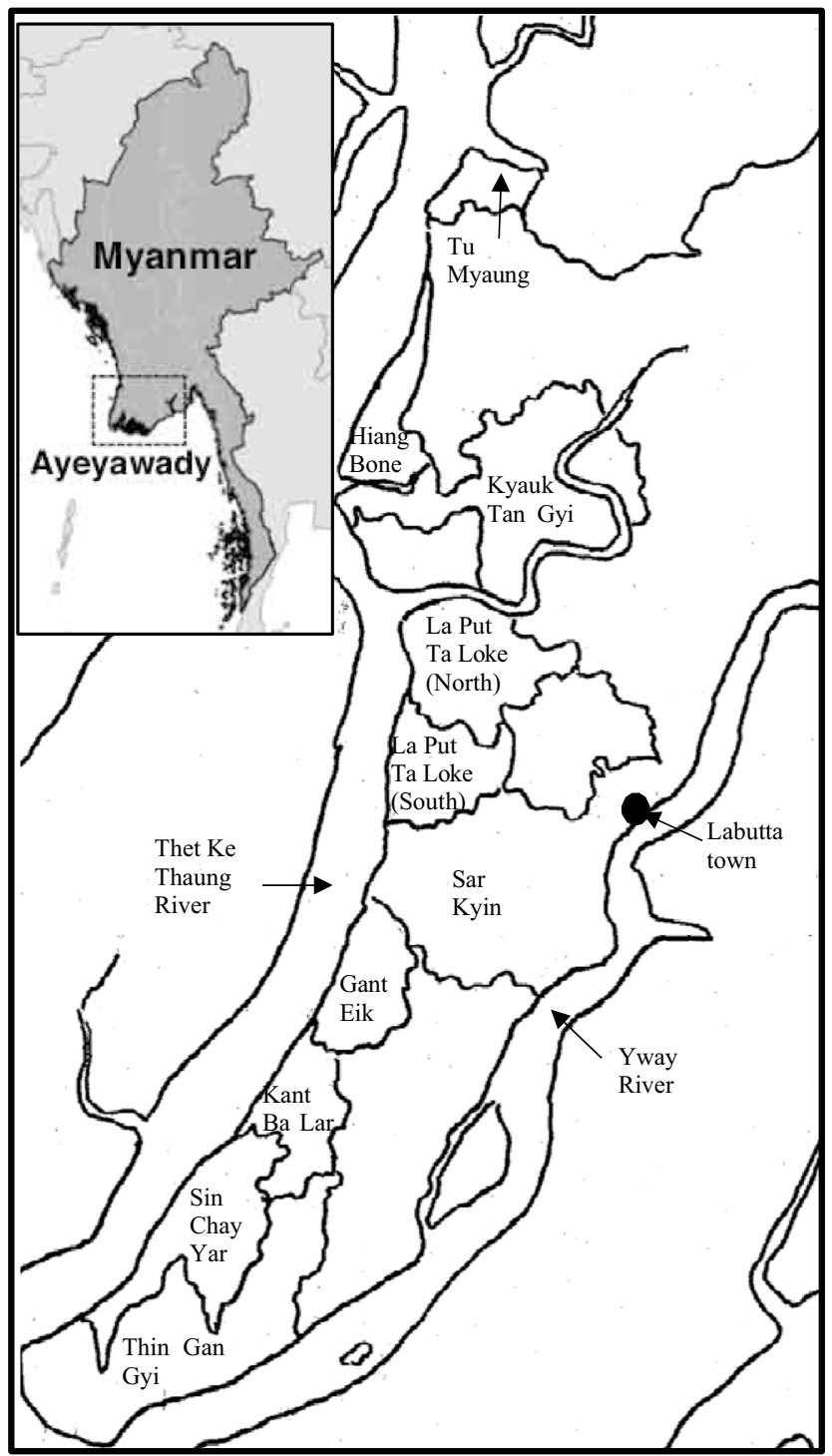

Fig. 1 Village tracts in Labutta township

Regarding the weather index for flood damage, the summation of rainfall during May-October in 2015 was $3,316 \mathrm{~mm}$. The reported flood damage area rate of the damaged farmer in the survey was $15 \%$. However, the rainfall in 2016 was $3,659 \mathrm{~mm}$. The damaged area rate was $24 \%$. Considering this relation between rainfall and the damaged area rate, the threshold of rainfall summation during May-October for WII was set to $3,500 \mathrm{~mm}$.

The coefficient of relative risk aversion (CoRRA), i.e., $\gamma$, was fixed at 0.68, except in the case of changes in CoRRA. This number was selected from "Risk-averse class," as calculated by Belissa et al. (2019).

\section{Results}

\section{Regression analysis of flood disaster area rates}

A linear function was estimated using OLS: the explained variable was the flood damaged area rate (\%). The explanatory variables were total rainfall during May-October in the rainy season, some farmer dummy variables, and year dummy variables. The farm dummies were introduced to show exceptional farmers who were damaged by flooding, although rainfall does not affect their agricultural activities. The year dummies were selected if $t$-values exceed $10 \%$ significance. The estimated linear function is shown as presented below: $\omega=\alpha_{0}+\beta_{B} B+\sum_{i} \beta_{D F i} D F_{i}+\sum_{j} \beta_{D Y j} D Y_{j}$.

In that equation, $\omega$ presents the rate of the flood damaged area (\%), $B$ stands for the total rainfall during May-October, $D F_{i}$ denotes a farm dummy variable for farm $i$, and $D Y_{j}$ expresses a yearly dummy variable for year $j$.

The estimation results are presented in Table 2. Results indicate that, if the total rainfall during May-October increases $1 \%$, the flood disaster area will increase $2.01 \%$ in cases where the parameter is evaluated by the average total rainfall, i.e., $3085 \mathrm{~mm}$.

\section{Calculation of optimum insurance payment}

For calculating an optimum insurance payment in the contract, the required dataset for a computation of Eq. (40) is created as shown in Table 3. These numbers are averages in Labutta township. The production function parameters $\beta_{V}-\beta_{S}$ are obtained by solving the profit maximization problem of a farmer in this township in the case of no risk. The summation of these parameters is 0.710 . However, all production parameters are scaled up by 1.408 because homogeneity of degree one is assumed for Eq. (30).

The calculated expectation optimum insurance payment using Eq. (40) in Labutta township is 271,100 Kyat, which is equivalent to around 193 US dollars. If the margin of the insurance company $m$ were $0.1 \%$ of the annual product value and if the contract year of this insurance were 5 years, which is almost equal to the flood disaster interval, i.e., $n=5$, then the calculated insurance premium based on Eq. (41) would be 58,000 Kyat per year, which is equivalent to around 42 US dollars. The share of this insurance premium is around $5 \%$ of rice cultivation income and around $2.7 \%$ of the total household income. These values are based on average numbers. Next, how the insurance payment and premium vary with changes in output price, rainfall, and CoRRA is investigated. 
Table 1 Sample farmer characteristics

\begin{tabular}{llll}
\hline Item & Sub-item & No & Unit \\
\hline Sex of rice cultivator & Male & 80.6 & $\%$ \\
& Female & 19.4 & $\%$ \\
Average cultivator age & & 49.9 & Years old \\
Buddhist share & & 100.0 & $\%$ \\
Barmar people share & & 99.7 & $\%$ \\
Education & No formal school & 14.1 & $\%$ \\
& Primary school (incomplete) & 3.1 & $\%$ \\
& Primary school completed (5 years of school) & 34.4 & $\%$ \\
& Secondary school (incomplete) & 20.0 & $\%$ \\
& Secondary school completed (9 years of school) & 9.4 & $\%$ \\
& Tertiary school (incomplete) & 6.6 & $\%$ \\
& Tertiary school completed (11 years of school) & 7.5 & $\%$ \\
& University (incomplete) & 1.6 & $\%$ \\
& University completed (15-18 years of school) & 3.4 & $\%$ \\
& & 23.8 & Years \\
Years of farming experience & With side job & 24.1 & $\%$ \\
Farmer with side job & Full time & 75.9 & $\%$ \\
& Share of rice income to total household income & 94.9 & $\%$ \\
\hline
\end{tabular}

Samples of 320 farmers

Figure 2 presents changes in insurance payments and premiums that occur with the increasing price of rice on an average farm. Fundamentally, the insurance payment is an input demand function of the farm under flood risk. If the output price increases, then the demand for insurance will increase. Following the calculation, if the price of rice increases from 300 to $320 \mathrm{Kyat} \mathrm{kg}^{-1}$, then the insurance payment can be expected to increase from 191,500 to 584,700 Kyat. According to the increase in the insurance payment, the premium can be expected to increase from 42,500 to 121,400 Kyat per year.

Next, effects of changes in rainfall are investigated. Figure 3 portrays changes in insurance payments and premiums with increases in all rainfall from May through October. In this model, if the total rainfall were to be less than $3,500 \mathrm{~mm}$, then the farmers would be ineligible to receive their insurance payments. If the rainfall were to exceed the threshold by $200 \mathrm{~mm}$, i.e., the rainfall reached $3,700 \mathrm{~mm}$, then the insurance payment would be 271,100 Kyat. The premium would be 54,200 Kyat per year.

In earlier analyses, the CoRRA is fixed at 0.68 , which is the number of Table 1A of Belissa et al. (2019). Finally, the effects of changes in CoRRA on the insurance payment
Table 2 Regression analysis results for rate of flood damage area

\begin{tabular}{|c|c|c|c|}
\hline Variable & Parameter & Unit & $t$-value \\
\hline Intercept & -1.27183 & $\%$ & -1.65 \\
\hline Total rainfall May-Oct & 0.00065 & $\% \mathrm{~mm}^{-1}$ & 2.56 \\
\hline LLS $49^{\text {th }}$ Farmer & 19.03042 & $\%$ & 12.89 \\
\hline LLN $20^{\text {th }}$ Farmer & 24.29709 & $\%$ & 16.46 \\
\hline LLN $27^{\text {th }}$ Farmer & 29.29709 & $\%$ & 19.84 \\
\hline Year 2009 & -0.52744 & $\%$ & -1.77 \\
\hline Year 2011 & -0.52242 & $\%$ & -1.81 \\
\hline Year 2014 & 0.75582 & $\%$ & 2.74 \\
\hline
\end{tabular}

Adj. $R^{2}, 0.2242$; number in sample, 2880 (320 farmers, 9 years);

LLS, Laputta Loke South village tract; LLN, Laputta Loke North village tract

are investigated. Figure 4 presents the relation between CoRRA and the insurance payment and premium. As this figure shows, if the CoRRA of a farmer approaches 1.0, then the insurance premium would be expected to increase drastically. For example, if CoRRA were to increase from 0.60 to 0.90 , then the insurance payment would increase from 
Table 3 Data used for optimum insurance payment calculation

\begin{tabular}{llll}
\hline Variable & Contents & Number & Unit \\
\hline$\omega$ & Flood damaged area rate & 0.929 & $\%$ \\
$\theta$ & Marginal damaged area rate & 0.00065 & $\% \mathrm{~mm}^{-1}$ \\
$B$ & Rainfall & 3,700 & $\mathrm{~mm}$ \\
$Z$ & Threshold & 3,500 & $\mathrm{~mm}$ \\
$p$ & Farm gate price of rice & 306 & $\mathrm{Kyat} \mathrm{kg}^{-1}\left(000 \mathrm{Kyat} \mathrm{t}^{-1}\right)$ \\
$q$ & Production of rice & 13.890 & $\mathrm{~kg}$ \\
$w_{V}$ & Fertilizer price & 630 & $\mathrm{Kyat} \mathrm{kg}^{-1}$ \\
$w_{L}$ & Wage rate & 2.5 & $000 \mathrm{Kyat} \mathrm{day}^{-1} \mathrm{person}^{-1}$ \\
$w_{K}$ & Capital user cost price & 1007 & $000 \mathrm{Kyat} \mathrm{tractor}^{-1}$ \\
$w_{S}$ & Land rent & 2,500 & $000 \mathrm{Kyat} \mathrm{acre}^{-1}$ \\
$x_{V}$ & Fertilizer and seed input & 1,128 & $\mathrm{~kg}^{-1}$ \\
$x_{L}$ & Labor input & 392.1 & Person day \\
$x_{K}$ & Capital input & 607.8 & Harvest fee $000 \mathrm{Kyat}^{-1}$ \\
$x_{S}$ & Land input & 13.77 & Acre \\
$\beta_{V}$ & Cost share of fertilizer and seed & 0.232 & Dimensionless \\
$\beta_{L}$ & Cost share of labor & 0.386 & Dimensionless \\
$\beta_{K}$ & Cost share of capital & 0.235 & Dimensionless \\
$\beta_{S}$ & Cost share of land rent & 0.146 & Dimensionless \\
$\gamma$ & Coefficient of relative risk aversion & 0.68 & Dimensionless \\
$m$ & Margin of the insurance company & 0.1 & $\%$ \\
\hline & & &
\end{tabular}

185,700 Kyat to 804,600 Kyat. However, the premium would not increase so much: only from 41,400 Kyat to 165,200 Kyat. These dramatic changes in the insurance payment result from specification of the utility function (2).

\section{Conclusions}

For rice farmers in Labutta township in the Ayeyarwady region in Myanmar, an optimum insurance payment and premium of an index insurance for flood disasters were calculated. A farmer has two faces: that of a producer of a firm creating agricultural products and that of a consumer, similar to an urban resident. In an ordinary case, a firm is presented as a neutral risk-taker; a consumer is presumed to be a risk-averter. In this insurance contract model, the farmers are assumed to be more similar to consumers and are assumed to be risk-averse.

In this model are set a profit maximization model considering insurance payments and premiums of a riskaverter. A function of the optimum insurance payment is derived from the input demand functions obtained by solving the utility maximization problem. The insurance premium of a risk-averter will be higher than that of other risk-takers if the neutral risk-taker demands insurance.

The optimum insurance payment of an average farm in Labutta township is obtained by substituting the flood damage area rate during the 9 years of 2008 through 2016, along with input prices, output prices, and cost shares into Eq. (40). Furthermore, the optimum insurance premium is calculated using Eq. (41). Results indicate that around 5\% of the rice production income is the optimum premium for a flood disaster for farmers in this region. The margin of the insurance company is assumed to be $0.1 \%$ of the yearly production value. A flood disaster is assumed to occur once every 5 years. The insurance premium is equivalent to around 41.5 US dollars. However, if farmers pay it, then they will maximize their benefits under the flood risk they face.

Hazell et al. (2010) of the International Fund for Agricultural Development (IFAD) and World Food Programme (WFP) reported some examples of WII from around the world. The WII developed by the national insurance 
Fig. 2 Relation between farm price of rice and insurance payments and premiums. Notes: rainfall from May to October, $3,700 \mathrm{~mm}$; coefficient of relative risk aversion, 0.68

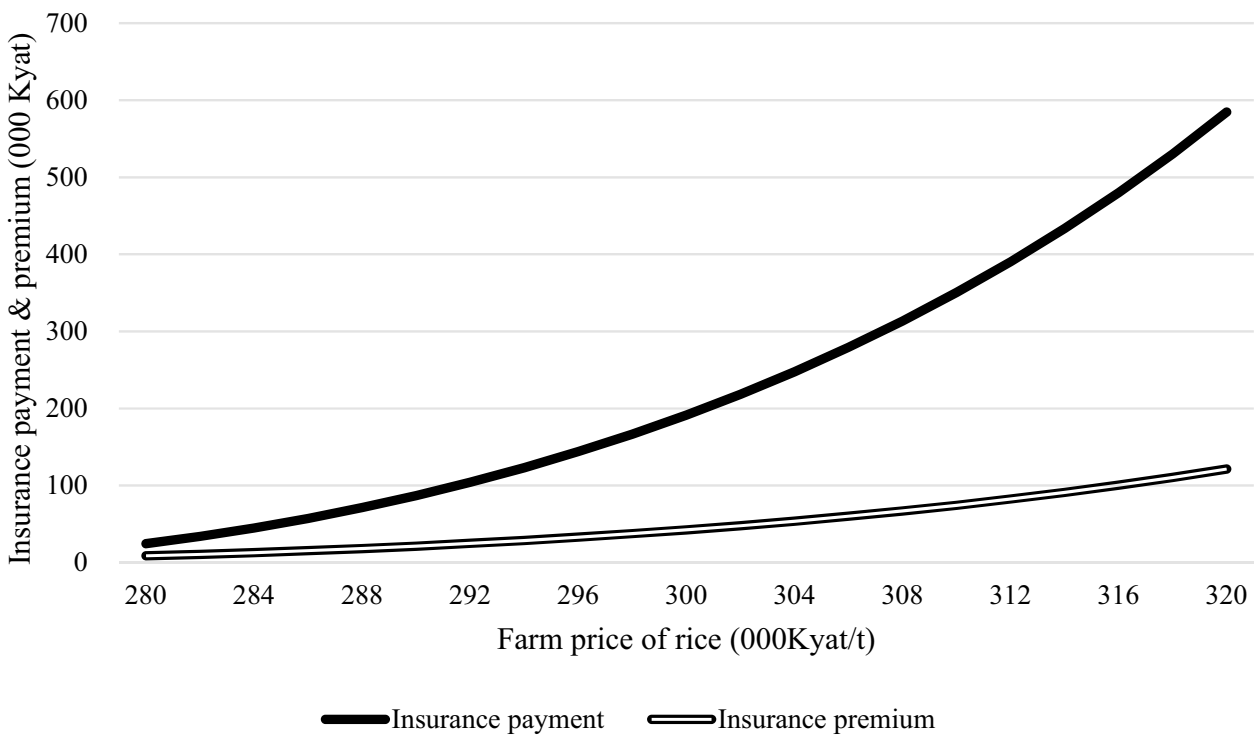

Fig. 3 Relation between rainfall during May to October and insurance payments and premiums. Notes: price of rice, 306,000 Kyat kg-1; coefficient of relative risk aversion, 0.68

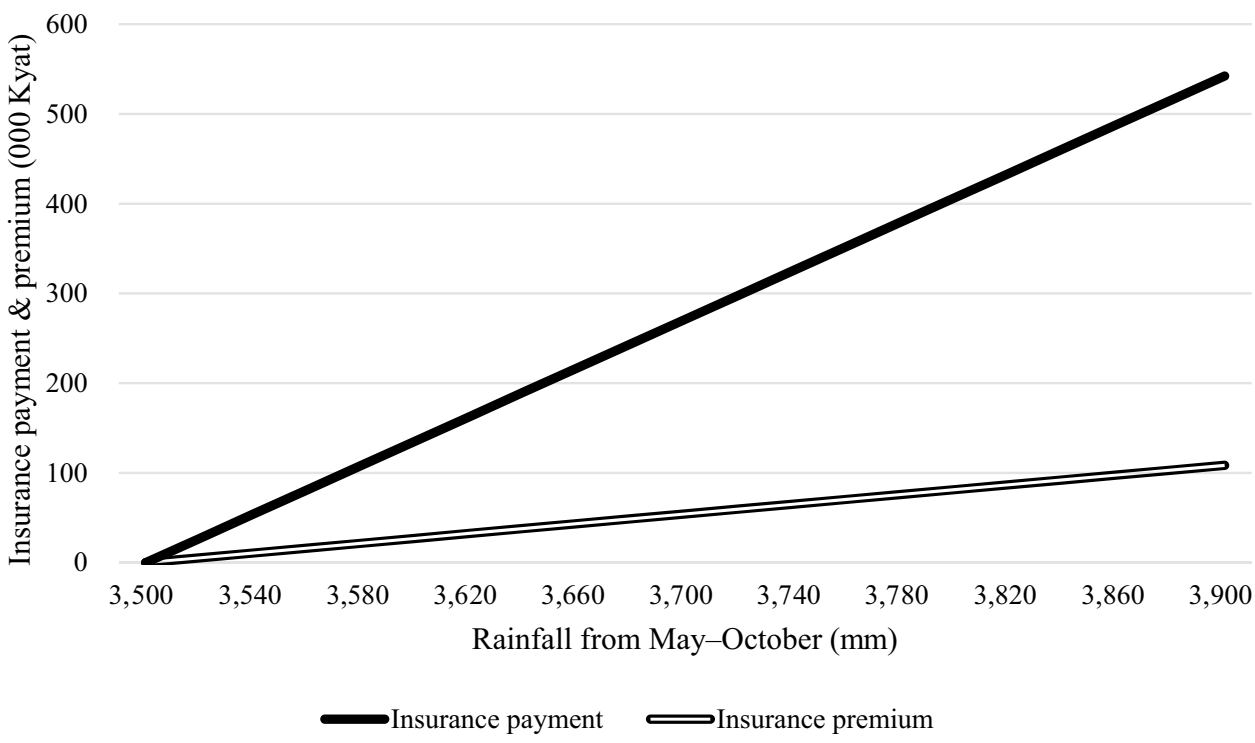

institution of government of Mexico targeted farmers who cultivated maize, beans, sorghum, and barley. The index was rainfall. The target disasters were drought and excess moisture. The insurance premium of this WII in 2008 was around 27.2 US dollars. The IFAD and the WFP conducted a pilot project of a WII with the Chinese Ministry of Agriculture. The target group was rice cultivation farmers in Anhui province. The indices were rainfall and temperature. The target disasters were drought and high temperature. The average insurance premium was 2.43 US dollars per hectare.

Some WIIs were developed in India. Hazell et al. (2010) reported that PepsiCo sold a WII to potato farmers in West Bengal, Punjab, and Uttar Pradesh states in 2007 and 2008. The indices were humidity and temperature. The target disaster was incidence of late blight disease. The insurance premium was 74.1 US dollars per hectare. Hazell et al. (2010) reported that ICICI Lombard General Insurance Company had sold WIIs from 2003. The target area and season were, respectively, Andhra Pradesh state and the monsoon season. The target groups were groundnut and castor farmers. The average insurance premium was 30.8 US dollars per farm.

The reported insurance premiums by this article vary depending on the country, kind of crop, and disaster type. The calculated Myanmar flood insurance is more expensive than the WIIs in Mexico, China, and Andhra Pradesh state in India. However, it is less expensive the than the WII of potato farmers in West Bengal, Punjab, and Uttar Pradesh states in India. The results obtained in this study for insurance premiums reflect higher rice production risks in this coastal region of Myanmar. Moreover, it is noteworthy that the index insurance proposed herein treats flood disasters, which are included among cyclone disasters. 
Fig. 4 Relation between CoRRA and insurance payments and premiums. Notes: price of rice, 306,000 Kyat $\mathrm{kg}^{-1}$; rainfall during May-Oct., $3700 \mathrm{~mm}$

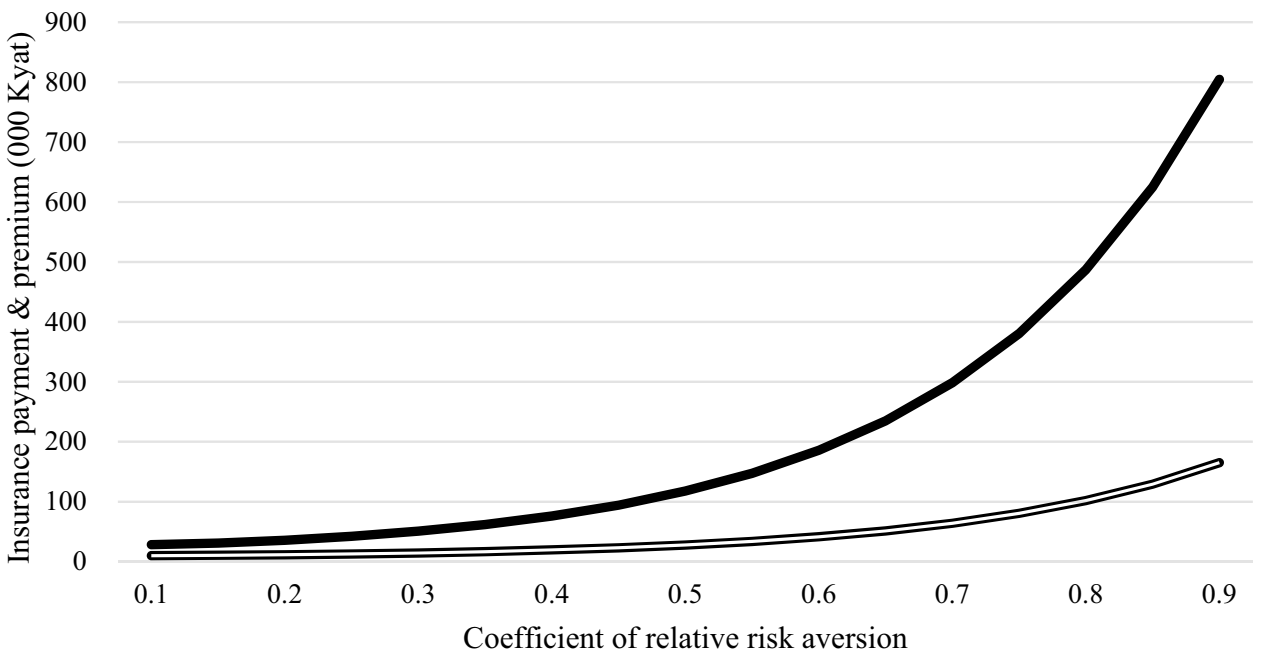

Insurance payment $\quad$ Insurance premium
Because of data limitations, the only index for the insurance examined in this study is rainfall. However, Labutta township is in a cyclone disaster-prone region. Saline damage by high tides is a crucially important issue for this region. Development of agricultural insurance, of which indices are the distance from the cyclone center or a river water level, is desired to produce a sustainable food supply.

Acknowledgements We extend our sincere appreciation to Professor Tetsushi Homma of the University of Toyama for advising selection of the utility function and derivation of the input demand and insurance payment functions in our model. This study was conducted using funds received from the JIRCAS project "Climate Change Measures in Agricultural Systems."

Open Access This article is licensed under a Creative Commons Attribution 4.0 International License, which permits use, sharing, adaptation, distribution and reproduction in any medium or format, as long as you give appropriate credit to the original author(s) and the source, provide a link to the Creative Commons licence, and indicate if changes were made. The images or other third party material in this article are included in the article's Creative Commons licence, unless indicated otherwise in a credit line to the material. If material is not included in the article's Creative Commons licence and your intended use is not permitted by statutory regulation or exceeds the permitted use, you will need to obtain permission directly from the copyright holder. To view a copy of this licence, visit http://creativecommons.org/licenses/by/4.0/.

\section{References}

Akter S, Krupnik TJ, Rossi F, Khanam F (2016) The influence of gender and product design on farmers' preferences for weatherindexed crop insurance. Glob Environ Chang 38:217-229. https:// doi.org/10.1016/j.gloenvcha.2016.03.010

Belissa TK, Lensink R, van Asseldonk M (2019) Risk and ambiguity aversion behavior in index-based insurance uptake decisions: experimental evidence from Ethiopia. Journal of Economic
Behavior and Organization, Available online 3 August 2019. https://doi.org/10.1016/j.jebo.2019.07.018

Cole S, Giné X, Vickery J (2017) How does risk management influence production decision? Evidence from a field experiment. Rev Financial Stud 30(6):1935-1970. https://doi.org/10.1093/ rfs/hhw080

Fritz HM, Blount CD, Thiwin S, Thu MK, Chan N (2009) Cyclone Nargis storm surge in Myanmar. Nat Geosci 2:448-449

Hill RV, Viceisza A (2012) A field experiment on the impact of weather shocks and insurance on risky investment. Exp Econ 15:341-371. https://doi.org/10.1007/s10683-011-9303-7

Htwe NM, Singleton GR, Nelson AD (2013) Can rodent outbreaks be driven by major climatic events? Evidence from cyclone Nargis in the Ayeyawady Delta, Myanmar. Pest Manag Sci 69:378-385. https://doi.org/10.1002/ps.3292

Hazell P, Anderson J, Balzer N, Clemmensen AH, Hess U, Rispoli F (2010) Potential for scale and sustainability in weather index insurance for agriculture and rural livelihoods, International Fund for Agricultural Development and World Food Programme, Rome. https://www.ifad.org/documents/38714170/40239486/The+poten tial+for+scale+and+sustainability+in+weather+index+insur ance+for+agriculture+and+rural+livelihoods.pdf/7a8247c7d7be-4a1b-9088-37edee6717ca

IPCC (2015) Climate Change 2014: Synthesis Report. Contribution of Working Groups I, II and III to the Fifth Assessment Report of the Intergovernmental Panel on Climate Change, IPCC, Geneva, Switzerland, 151pp. https://www.ipcc.ch/site/assets/uploads/2018/ 05/SYR_AR5_FINAL_full_wcover.pdf

de Janvry A, Sadoulet E, Suri T (2017) Chapter 5. Field experiments in developing country agriculture. Handbook of field experiments 2, North Holland, Amsterdam, pp 432-434

Jin J, Wang W, Wang X (2016) Farmers' risk preferences and agricultural weather index insurance uptake in rural China. International Journal of Risk Science 7:366-373

Karlan D, Osei R, Osei-Akoto I, Udry C (2014) Agricultural decisions after relaxing credit and risk constraints. Q J Econ 129(2):597652. https://doi.org/10.1093/qje/qju002

Mahul O (2001) Optimal insurance against climatic experience. Am J Agr Econ 83(3):593-604. https://doi.org/10.1111/0002-9092.00180

McIntosh C, Sarris A, Papadopoulos F (2013) Productivity, credit, risk, and the demand for weather index insurance in smallholder agriculture in Ethiopia. Agricultural Economics 44: 399-417 
Shirsath P, Vyas S, Aggarwal P, Rao KN (2019) Designing weather index insurance of crops for the increased satisfaction of farmers, industry and the government. Clim Risk Manag 25. https://doi. org/10.1016/j.crm.2019.100189

Thein S, Diepart JC, Moe H, Allaverdian C (2018) Large-scale land acquisitions for agricultural development in Myanmar: a review of past and current processes. MRLG Thematic Study Series 9, Vientiane, Lao PDR, pp 33
Turvey CG, Weersink A, Chiang SC (2006) Pricing weather insurance with a random strike price: the Ontario ice-wine harvest. Am J Agr Econ 88(3):696-709. https://doi.org/10.1111/j.1467-8276. 2006.00889.x

World Bank (2011) Weather index insurance for agriculture: guidance for development practitioners, Agriculture and rural development discussion paper 50, Washington DC, pp 9-13 